\title{
Analisis Paralelisasi Konverter Melalui Multi Input - Single Output Transformator Frekuensi Tinggi dengan MatLab Simulink
}

\author{
Fitriadi $^{\text {1*}}$, Valdi Rizki Yandri ${ }^{2}$, Herisajani ${ }^{3}$ \\ 1,2,3 Jurusan Teknik Elektro, Politeknik Negeri Padang \\ Jurusan Teknik Elektro Politeknik Negeri Padang, Jl. Limau Manih Padang, 25164, Indonesia \\ *Corresponding Author, email: fitriadichng@gmail.com
}

\begin{abstract}
Abstrak- Dua konverter DC/AC yang bekerja dengan secara isolated control dapat diparalelkan dengan transformator frekuensi tinggi dengan sebuah pola switching. Namun, pola switching dan teknik pengontrolan konverter tersebut perlu penelitian lebih lanjut agar proses penyaluran energi listrik pada sisi output paralelisasi dapat menghasilkan nilai optimum. Dalam penelitian ini dikembangkan metode paralelisasi dua buah konverter pada sebuah transformator frekuensi tinggi dengan kapabilitas multi input-single output menggunakan Matlab/Simulink. Sisi input transformator terdiri dari dua buah konverter jembatan penuh, sementara sisi sekunder mewakili sisi output paralelisasi. Dua konverter DC/AC disimulasikan dengan pola switching phase shifted full bridge (PSFB) dan teknik kontrol voltage mode control (VMC). Kondisi penyaluran optimum energi diinvestigasi dengan melihat pengaruh besarnya lama kondisi ON setiap setengah siklus periode switching masing-masing konverter input terhadap lamanya kondisi ON pada terminal belitan transformator pada sisi sekunder (output). Lama kondisi ON setiap konverter dengan pola switching PSFB merupakan sebuah kondisi yang bergantung pada fasa shifted/delay sinyal kontrol gate. Hasil simulasi menunjukan kondisi ON optimum terjadi ketika fasa shifted/delay sinyal kontrol gate masing-masing konverter adalah $135^{\circ}\left(\alpha 1=\alpha 2=135^{\circ}\right)$ jika dibandingkan pada kondisi shifted/delay sinyal kontrol gate masing-masing konverter $\alpha 1=\alpha 2=$ $4^{\circ}$. Hal ini menunjukan nilai optimum penyaluran dari konverter terjadi ketika nilai $\alpha$ kedua konverter besar.
\end{abstract}

Kata kunci : paralelisasi, konverter, transformator, coupled magnetic

Abstract-Two parallel converters DC/AC with isolated control can be applied by a high frequency transformer with a switching pattern. However, the switching pattern and control technique of the converter needs more research so the process of electrical energy distribution on the parallel output side can produce the optimum value. Furthermore, in this research, parallelization method is applied by utilizing two converters in high frequency transformer with multi input-single output capability controlled by Matlab/Simulink. The input side of transformer consists of two full bridge converters while secondary side represents the parallelization of output side. Two converters DC/AC is simulated by phase shifted full bridge (PSFB) of switching pattern and voltage mode control (VMC) technique. The distribution condition of optimum energy is investigated by observation of influences of ON condition duration of each switching period cycle on input converter to ON condition duration of secondary transformer terminal. The ON condition duration of each converter with switching PSFB is the condition depends on shifted/delay phase of signal on gate control. According to this simulation, optimum $O N$ condition occurs when shifted/delay phase of each gate control signal converter is $135^{\circ}\left(\alpha_{1}=\alpha_{2}=135^{\circ}\right)$ and this condition is more efficient than phase of gate control signal is $45^{\circ}\left(\alpha_{1}=\alpha_{2}=45 \%\right.$. The simulation results show that larger $\alpha$ of converters give the optimum distribution.

Keywords: parallelization, converter, transformer, coupled magnetic

\section{PENDAHULUAN}

Persoalan pada aplikasi energi terbarukan sebagai sumber energi listrik alternatif belum optimal dikarenakan sumber energi utama yang berfluktuasi serta ketersediaannya tidak selalu ada dalam satu rentang (periode waktu) akibatnya suplai daya kebeban tidak terjamin. Misalkan energi angin dan solar sel.

Untuk menjamin ketersediaan suplai daya ke beban maka dilakukanlah langkah paralelisasi dua atau lebih pembangkit yang bersumber dari energi terbarukan, baik yang sejenis maupun tidak. Sementara itu metode paralelisasi yang telah berkembang seperti yang dilaporkan pada [1]-[3] dimana paralelisasi beberapa pembangkit energi terbarukan dapat dikelompokkan berdasarkan tegangan paralelisasinya yang dikenal dengan metode DC-Coupled Systems, AC-Coupled Systems dan Hybrid-Coupled Systems.

Metode lain tetang paralelisasi pembangkit sumber energi terbarukan yaitu hybrid coupled magnetic system dengan menggunakan transformator seperti yang dilaporkan oleh [2],[3]. Meskipun topologi-topologi paralelisasi yang ada memiliki kelebihan namun juga memiliki kekurangan seperti metode paralelisasi yang dikembangkan oleh [2], dimana paralelisasi dua konverter dengan satu inti transformator jauh lebih baik dibandingkan dengan tiga inti yang terpisah. Namun kelemahannya, jumlah konverter pembangkit yang diparalelisasi terbatas oleh besarnya inti transformator yang digunakan. Selanjutnya metode paralelisasi yang dikembangkan oleh [3], dimana dua konverter pembangkit sumber energi terbarukan diparalelisasi dengan menggunakan Interphase Transformer (IPT). Paralelisasi dengan metode ini dapat memparalelkan lebih banyak konverter pembangkit, namun kelemahannya kemungkinan akan terjadi sirkulasi arus antar konverter yang diparalelisasi. Dalam paper ini dikembangkan 
metode paralelisasi konverter-konverter pembangkit energi terbarukan dengan menggunakan metode hybrid coupled magnetic system dengan Matlab Simulink. Paralelisasi dua konverter menggunakan transformator frekuensi tinggi dengan kapabilitas multi input-single output. Dengan menggunakan transformator frekuensi tinggi terbukti secara ukuran jauh lebih kecil dengan daya yang sama dibandingkan dengan transformator konvensional seperti yang telah dikembangkan pada [4].

Permasalahan yang dihadapi dalam metode hybrid coupled magnetic systems adalah bagaimana mentransfer energi yang optimum dari sisi primer menuju sisi sekunder transformator frekuensi tinggi. Berbagai litertur [4],[5] menyatakan transfer energi yang optimum dapat dilakukan melalui pengaturan pola switching dengan bentuk gelombangnya persegi (square wave), serta penggunaan material inti transformator dan frekuensi operasinya. Namun demikian, kesemua faktor ini masih perlu diinvestigasi lebih lanjut.

Terkait dengan pola switching haruslah memiliki desain sehingga dapat menjamin energi yang disalurkan dari masing-masing konverter input tersalurkan ke sisi sekunder. Salah satu metode membangkitkan pola switching yang prosfektif diterapkan pada sistem paralelisasi adalah dengan metode phase shifted full bridge. Metode ini simple dan dapat dapat direalisasikan secara analog maupun secara digital menggunakan mikrokontroler, DSP dan peralatan kontrol digital lainya. Selanjutnya, persoalan lain dari paralelisasi dengan metode hybrid coupled magnetic systems adalah menyangkut desain transformator yang digunakan. Transformator yang digunakan haruslah memiliki kapabilitas multi input-single output dan dapat dioprasikan pada frekuensi tinggi.

Maka tujuan dari penelitian ini menginvestigasi secara simulasi tentang pola switching masing-masing konverter agar dapat menyalurkan energi listrik yang optimum pada sisi output transformator.

\section{METODE}

Sebuah metode paralelisasi yang dikembangkan dalam paper ini ditunjukan oleh Gambar 1. Pada gambar terlihat dua konverter diparalelkan melalui sebuah transformator frekuensi tinggi dengan kapabilitas multi input-single output. Sisi input transformator terdiri dari dua buah konverter DC/AC yang mewakili konverter-konverter pembangkit sumber energi terbarukan, sementara sisi sekunder mewakili sisi output paralelisasi.

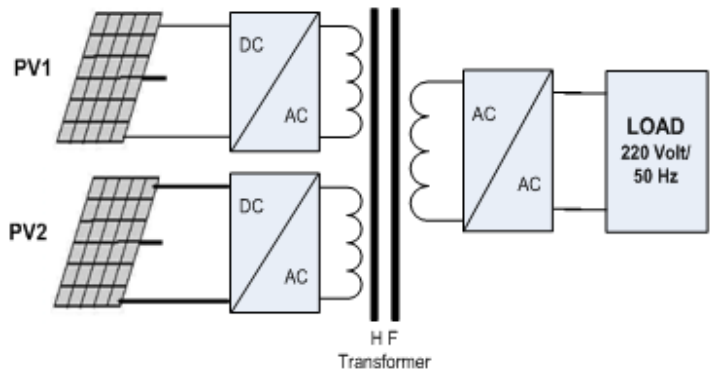

Gambar 1. Pemodelan paralelisasi konverter dengan metode hybrid coupled magnetic systems

Paralelisasi dengan metode coupled magnetic system ini dapat dilakukan dengan menggunakan pola switching yang tepat. Untuk menghasilkan pola switching tersebut konverter-konverter sisi input didesain dengan topologi full-bridge dan dioperasikan dengan metode phase shifted full bridge (PSFB) dan teknik kontrol voltage mode control (VMC) [5]-[10] seperti yang ditunjukan pada Gambar 2.

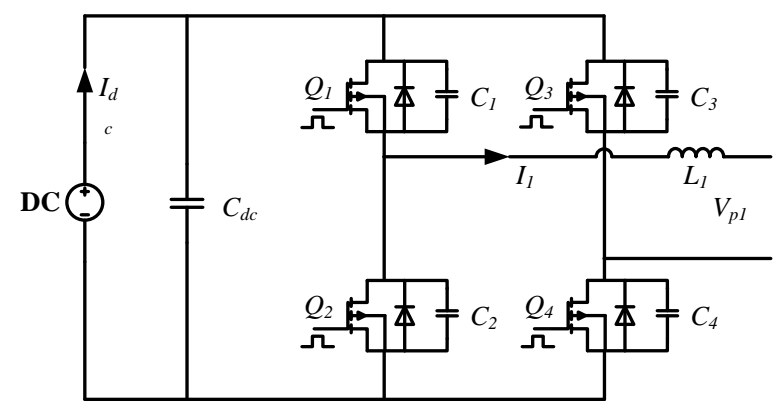

Gambar 2. Topologi rangkaian daya full-bridge converter

Sinyal PWM dihasilkan dari sinyal repetitif berbentuk gelombang gergaji (Repeating Sequence) dengan besar matrik algoritma dan amplitudo untuk satu perioda $(T)$ gelombang dapat diatur pada sebuah blok parameter. Dalam simulasi ini nilai matrik algoritma untuk sinyal repetitif adalah $[00.0050 .01]^{*} 0.005$, maka

$$
T=0,01 \times 0,005=0.00005
$$

sedangkan setengah perioda adalah.

$$
T / 2=0,000025
$$

sedangkan nilai matrik amplitudo gelombang [0 10 ll. Maka besarnya frekuensi switching adalah.

$$
f=1 / T=50 \mathrm{kHz}
$$

Kemudian sinyal repetitif ini dibandingkan dengan sinyal kontrol dengan nilai konstan (tetap) menggunakan Relational Operator. Sinyal kontrol diatur sebesar 0,5 untuk mendapatkan output sinyal PWM dengan duty-cycle $50 \%$ seperti yang ditunjukan pada Gambar 3 .

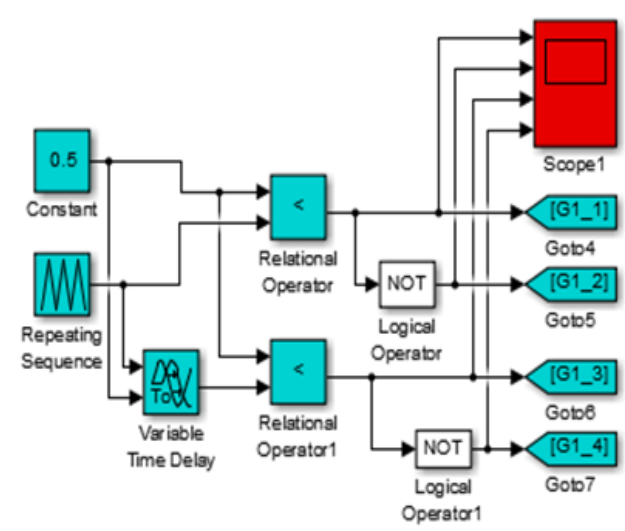

Gambar 3. Pemodelan pembangkitan sinyal PWM dengan Matlab

Konveter full-bridge yang bekerja dengan teknik teknik kontrol VMC, dimana sinyal kontrol PWM yang ditunjukan oleh Gambar 4 di-input-kan pada kaki gate MOSFET secara half-bridge. Untuk leg $1(Q 1, Q 2)$ sinyal kontrol PWM dengan lebar turn-ON dan turn-OFF sebesar 
$\beta=180^{\circ}$ atau setengah perioda dengan duty cycle $50 \%$ pada frekuensi konstan $50 \mathrm{kHz}$ di-input-kan pada $Q 1$, kemudian inverse dari sinyal kontrol PWM $Q 1$ di-inputkan pada $Q 2$. Untuk half-bridge konverter berikutnya leg $2(Q 3, Q 4)$ sinyal kontrol PWM dengan duty cycle $50 \%$ pada frekuensi konstan di-delay/shifted sudut fasa sebesar $\alpha^{0}$ terhadap sinyal kontrol PWM pada leg 1. Delay/shifted sudut fasa ini agar terjadinya overlap pada kondisi turn$O N$ dalam waktu bersamaan secara diagonal. Konverter dengan teknik kontrol VMC ini semakin lama waktu overlap pada saat turn-ON semakin lama pula kondisi waktu tegangan di-input-kan pada sisi primer kumparan transformator, dengan demikian semakin besar jumlah energi yang ditransfer ke sisi sekunder transformator [10].

Paralelisasi dua konverter DC/AC yang disimulasikan dengan Matlab Simulink. Dimana komponen swtching MOSFET yang rangkai dengan topologi full-bridge dibangun dari SimPower System Toolbox. Transformator multi input-single output digunakan dua buah element linear transformer. Untuk single output disisi sekunder transformator kumparan diserikan seperti yang ditunjukan pada Gambar 5.

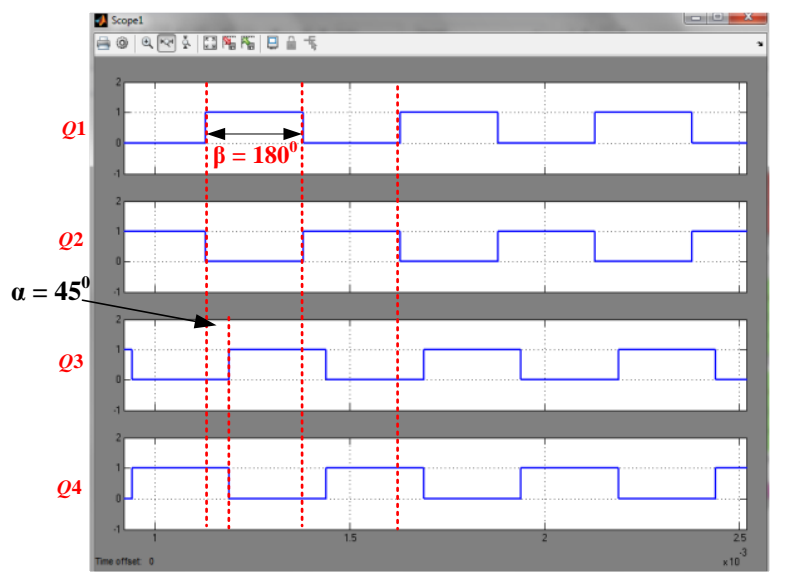

Gambar 4. Bentuk gelombang sinyal PWM dengan $\beta=180^{\circ}$ dan delay/shifted sudut fasa sebesar $\alpha=45^{\circ}$
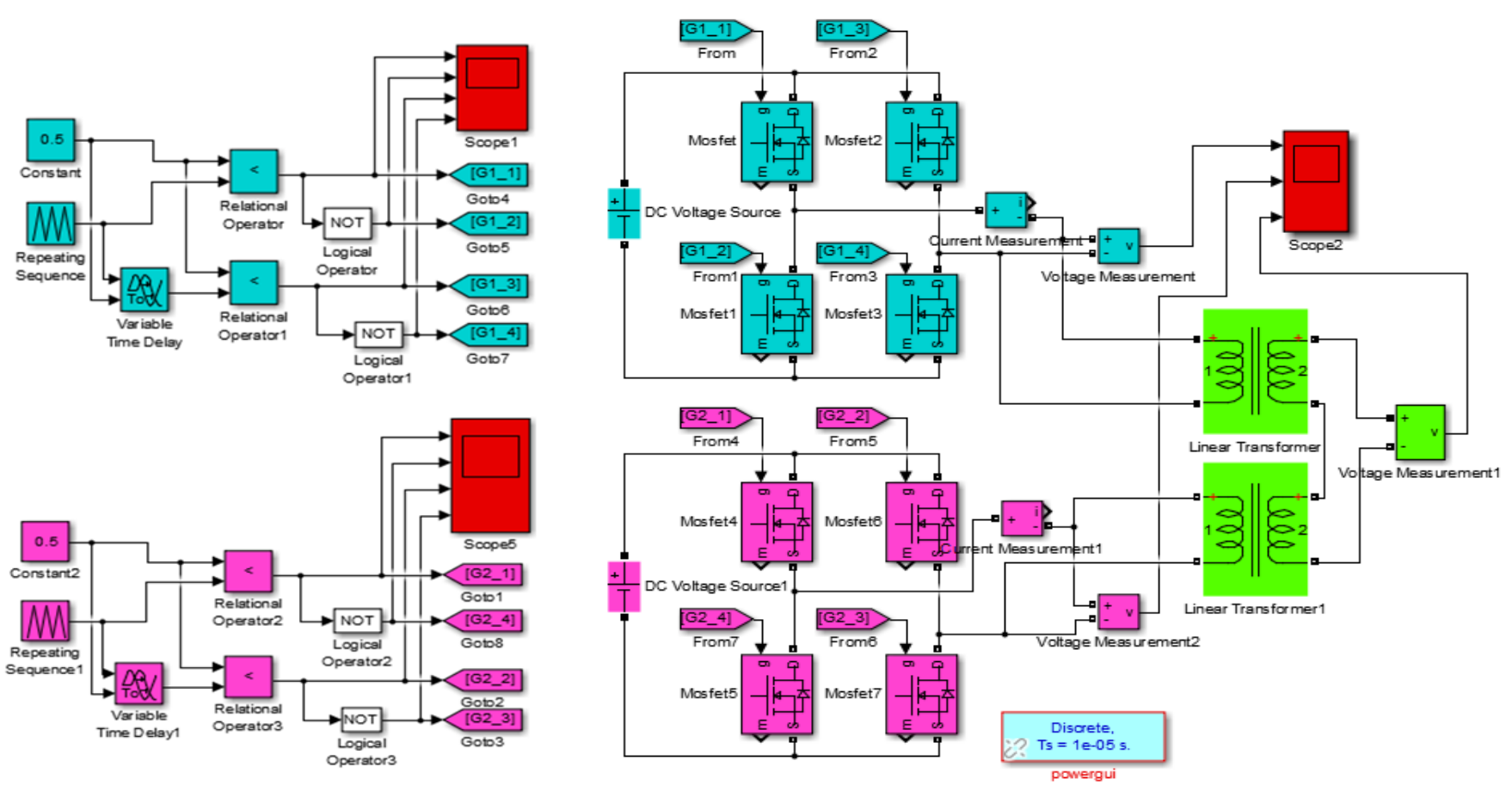

Gambar 5. Paralelisasi konverter-konverter pembangkit sumber energi terbarukan dengan Matlab Simulink

\section{HASIL DAN PEMBAHASAN}

Untuk melihat lamanya kondisi ON output dari masing-masing konverter, maka delay/shifted divariasikan kecil dari sudut $\beta=180^{\circ}$. Dalam simulasi ini delay/shifted sudut $\alpha^{0}$ masing-masing konverter adalah $45^{0}$ nilai ini mewakili delay/shifted seper empat dari $T / 2$ dan $135^{\circ}$ mewakili delay/shifted tiga per empat dari $T / 2$. Berikut ini, bentuk gelombang output dari masing-masing konverter dengan memvariasikan delay/shifted sudut $\alpha^{0}$ : (1) Phase shifting $\alpha 1=\alpha 2=45^{\circ}$; (2) Phase-shifting $\alpha 1=$ $45^{0}$ dan $\alpha 2=135^{\circ}$; (3) Phase-shifting $\alpha 1=\alpha 2=135^{0}$ adalah sebagai berikut :

\section{Phase shifting $\alpha 1=\alpha 2=45^{\circ}$}

Untuk mendapatkan sinyal kontrol PWM yang didelay/shifted sudut fasa sebesar $\alpha 1=\alpha 2=45^{\circ}$ dengan mengatur delay pada blok parameter variable time delay sebesar $(0.005 * 0.005 * 0.25)=0.00000625$ detik. Hasil simulasi menunjukan bentuk gelombang output dari masing-masing konverter sama dengan kondisi $O N$ kecil. Bentuk gelombang pada sisi primer output dari konverter dan sisi sekunder transformator dapat dilihat pada Gambar 6. Dari gambar juga terlihat bentuk gelombang output-nya sefasa dengan gelombang output konverter. 


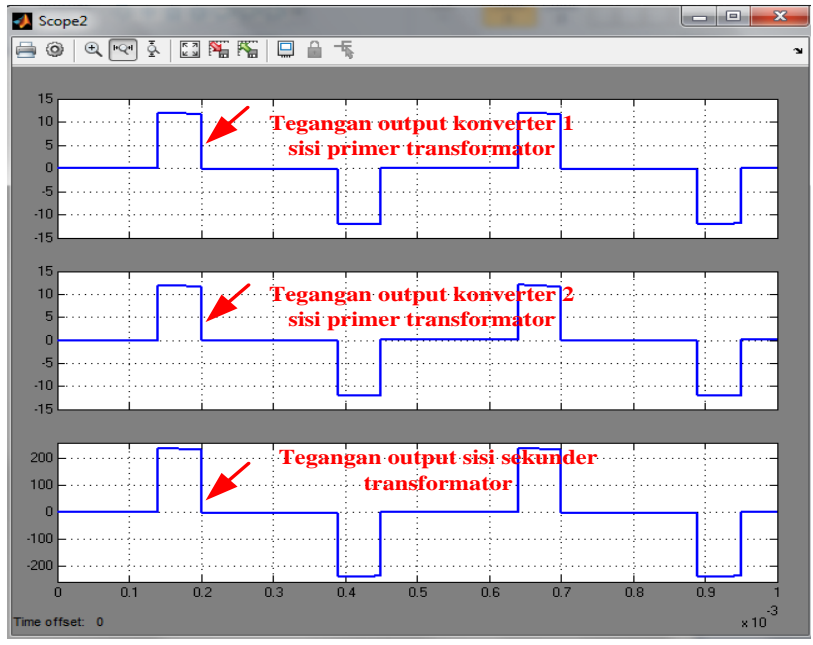

Gambar 6. Bentuk gelombang sisi primer dan sisi sekunder transformator dengan phase-shifting dan $\alpha 1=\alpha 2$ $=45^{0}$

\section{Phase-shifting $\alpha 1=45^{\circ}$ dan $\alpha 2=135^{\circ}$}

Simulasi kedua ini, delay/shifted sudut fasa dari masing-masing konverter daya didesain tidak sama. Pada konverter pertama sudut fasa sinyal kontrol PWM didelay/shifted sebesar $\alpha 1=45^{\circ}$, untuk konverter kedua sudut fasa sinyal kontrol PWM di-delay/shifted sebesar $\alpha 2$ $=135^{\circ}$. Hasil simulasi yang ditunjukan pada Gambar 7, bentuk gelombang pada sisi primer output dari konverter dan sisi sekunder transformator output dari masing-masing konverter tidak sefasa. Pada sisi sekunder output paralelisasi menghasilkan rugi-rugi daya yang besar.

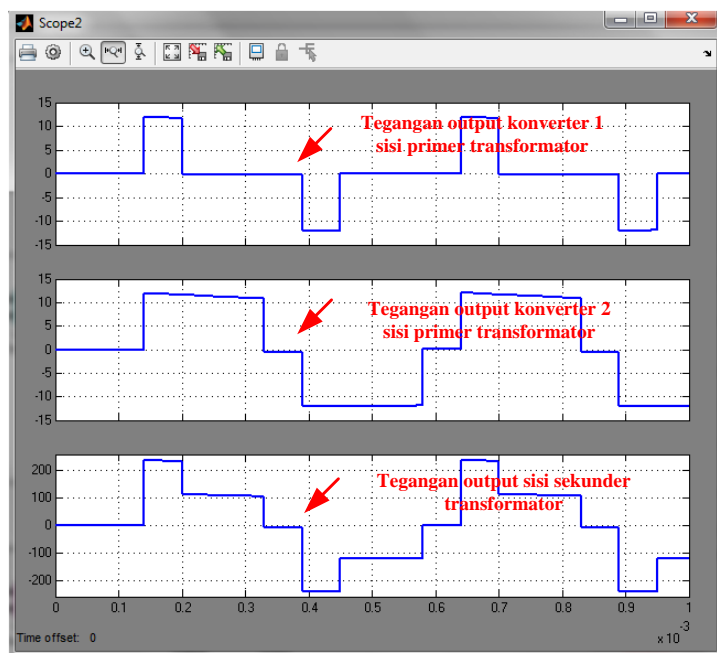

Gambar 7. Hasil simulasi gelombang output konverter terhubung pada kumparan primer dengan phase shifting $\alpha 1=45^{\circ}$ dan $\alpha 2=135^{\circ}$.

\section{Phase-shifting $\alpha 1=\alpha 2=135^{0}$}

Simulasi selanjutnya, delay/shifted sudut fasa dari masing-masing konverter daya dibuat sama dengan sudut fasa sinyal kontrol PWM di-delay/shifted sebesar $\alpha 1=\alpha 2$ $=135^{\circ}$. Pada blok parameter variable time delay pada masing-masing konverter daya diatur dengan waktu delay-nya sebesar $(0.005 * 0.005 * 0.75)=0.00001875$ detik.

Hasil simulasi dari phase-shifting $\alpha 1=\alpha 2=135^{\circ}$ menunjukan bentuk gelombang output dari masingmasing konverter pada kondisi $O N$ menghasilkan daya yang lebih besar dan juga sefasa, sedangkan pada sisi sekunder yang merupakan output paralelisasi energi yang ditransfer pada kondisi $O N$ juga lebih besar. Dari simulasi sistem ini dapat disimpulkan semakin besar waktu delay/shifted sudut fasa sinyal kontrol PWM semakin lama pula tegangan saat di-input-kan kesisi primer transformator seperti yang ditunjukan oleh Gambar 8.

Simulasi ini menunjukan sebuah pola switching yang optimum untuk mentransfer energi listrik ke sisi sekunder transformator berdasarkan besarnya energi yang ditransfer adalah dengan delay/shifted sudut fasa yang paling lebar serta kecil dari sudut $\beta$. Dalam simulasi ini didapatkan delay/shifted sudut fasa adalah dengan nilai $\alpha 1=\alpha 2=135^{\circ}$ menghasilkan waktu kondisi $O N$ lebih besar di bandingan dengan nilai $\alpha 1=\alpha 2=45^{\circ}$ hal ini juga telah dikembangkan oleh [9]. Pola switching inilah yang nantinya akan diterapkan pada konverter-konverter sisi input transformator pada tahapan realisasi prototype sistem.

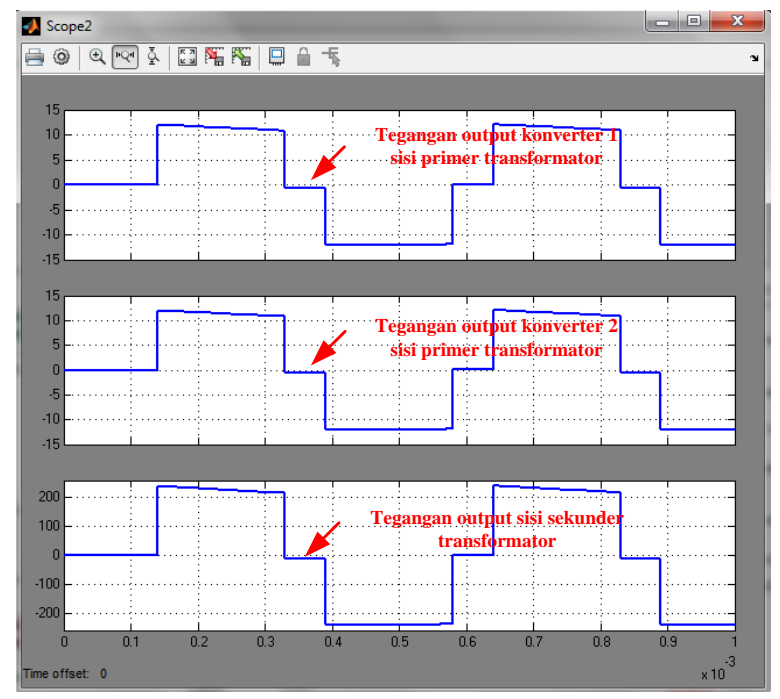

Gambar 8. Hasil simulasi gelombang output konverter terhubung pada kumparan primer dengan phase-shifting $\alpha 1$ $=\alpha 2=135^{\circ}$.

\section{KESIMPULAN}

Kontribusi yang diberikan dari penelitian ini adalah memperlihatkan dalam level simulator Matlab Simulink metode hybrid coupled magnetic system dalam memparalelisasikan dua konverter dengan transformator frekuensi tinggi. Hasil simulasi menunjukan kondisi ON optimum terjadi ketika fasa shifted/delay sinyal kontrol gate masing-masing konverter adalah $135^{\circ}\left(\alpha 1=\alpha 2=135^{\circ}\right)$ jika dibandingkan pada kondisi shifted/delay $\alpha 1=\alpha 2=45^{\circ}$. Hal ini menunjukan nilai optimum penyaluran dari konverter terjadi ketika nilai $\alpha$ kedua konverter besar 


\section{REFERENSI}

[1] Nehrir M. H., Wang C., Strunz K., Aki H., Ramakumar R., Bing J., Miao Z., Salameh Z.; A Review of Hybrid Renewable/Alternative Energy Systems for Electric Power Generation: Configuration, Control, and Applications. IEEE Transactions on Sustainable Energy, Vol. 2, No. 4, October 2011, pp. 392-403.

[2] Kabalci E.; Design And Analysis Of A Hybrid Renewable Energy Plant With Solar And Wind Power. Energy Conversion and Management 72, 51-59, 2013.

[3] Krishnamoorthy H.S., Essakiappan. S., Enjeti. P. N., Balog. R. S. Ahmed. S.; A New Multilevel Converter for Megawatt Scale Solar Photovoltaic Utility Integration. Twenty-Seventh Annual IEEE, Applied Power Electronics Conference and Exposition (APEC), 2012, pp. 1431-1438.

[4] Arikan. O., Isen. E., Durusu. A., Kekezoglu. B., Bozkurt. A., Erduman. A. Introduction to Hybrid Systems - Yildiz Technical University. EuroCon IEEE. 1-4 July 2013. Zagreb, Croatia.

[5] Irawan. J. A., Firmansyah. E., Wijaya. F. D.; Perancangan Transformator Frekuensi Tinggi untuk Konverter DC-DC FullBridge Phase-Shifted 200 W. Seminar Nasional Aplikasi Teknologi Informasi (SNATI) 2013 Yogyakarta, 15 Juni 2013.

[6] Puyal. D., Barragán. L. A., Acero. J.; An FPGA-Based Digital Modulator for Full- or Half-Bridge Inverter Control. IEEE Transactions On Power Electronics, Vol. 21, No. 5, September 2006.

[7] Fitriadi, Hamid. M. I.; Desain Rangkaian Gate-Driver Untuk Konverter Yang Bekerja Dengan Voltage Mode Control. Jurnal Nasional Teknik Elektro. Vol: 5 No. 2 Juli 2013.

[8] Arya. P. S., Chithra. R.; Phase Shifted Full Bridge DC-DC Converter. International Research Journal of Engineering and Technology (IRJET). Volume: 02 Issue: 04. July-2015.

[9] Texas Instruments.; Phase-Shifted Full Bridge DC/DC Power Converter Design Guide. May 2014.

[10] Nene. H.; Implementing advanced control strategies for phaseshifted, fullbridge DC/Dcconverters using MCUs (Part lof 2). Systems and Applications, for Texas Instruments Incorporated. 2000 